\author{
T. C. Jansen \\ E. J. O. Kompanje \\ C. Druml \\ D. K. Menon \\ C. J. Wiedermann \\ J. Bakker
}

\section{Reply to Moser and Röggla}

Accepted: 16 April 2007

Published online: 1 June 2007

(C) Springer-Verlag 2007

This reply refers to the comment available at: http://dx.doi.org/10.1007/ s00134-007-0701-4.

Sir, We thank Moser and Röggla for their comments [1]. We agree that it is preferable to use study data of patients who died before deferred consent could be sought. As we described, not only does discarding data probably jeopardize study results by introducing selection bias, it also has other negative scientific and ethical effects [2].

However, implementing a policy that allows the use of all data of deceased patients without any consent, principally assuming that patients or relatives do not object, can be undesirable, in our opinion. If a time limit for seeking deferred consent $(72 \mathrm{~h}$ is our recommendation) is not used, this might prevent researchers from seeking consent as early as possible, provided there are no other laws in a specific country for such situations. From a researchers' point of view, it would be beneficial to postpone seeking consent, as this would increase the chance of including data in the analysis. The only importance of the time limit of $72 \mathrm{~h}$ is to prevent unauthorized use of the obligation to seek consent. If there would be no such obligation, then a deferred consent procedure would be equal to a complete waiver of consent.

We disagree that implementing a time limit of $72 \mathrm{~h}$ would be impractical. This is illustrated by the questionnaire among clinicians in the field of neuro-critical care [3], and by the experiences in the early lactatedirected therapy study, in which the median time from randomization to consent was only 1 day (interquartile range 0-3 days) and in which none of the deceased patients without consent had to be excluded due to overshooting the time limit [2]. It is clinically practical to approach relatives within a time period of $72 \mathrm{~h}$.

We support initiatives to explore alternatives for solving this ethical dilemma. In our opinion, instead of using a 72-h threshold, consultation of an independent physician could also ascertain whether sufficient care has been taken to seek consent prior to death, in order to legitimately use the data. Although the idea of Moser and Röggla to create a research objection registry might seem attractive, we remind the research community that objecting to organ transplantation is of post-mortem importance, whereas experimental emergency research may have serious risks during life [4]. Furthermore, individuals can make valid predictions and considerations regarding organ-donation decisions, whereas in a research registry it would be impossible to assess the risk/benefit ratio of a particular future research project beforehand. Lastly, we doubt that such a registry would be more cost-effective and practical than using data of patients who died early (within $72 \mathrm{~h}$ ) without consent.

\section{References}

1. Moser B, Röggla G (2007) Not using data of patients who die before deferred informed consent potentially jeopardises emergency medical trials. Intensive Care Med 10.1007/ s00134-007-0701-4

2. Jansen TC, Kompanje EJ, Druml C, Menon DK, Wiedermann CJ, Bakker J (2007) Deferred consent in emergency intensive care research: What if the patient dies early? Use the data or not? Intensive Care Med 33(5):894-900

3. Kompanje EJ, Maas AI, Hilhorst MT, Slieker FJ, Teasdale GM (2005) Ethical considerations on consent procedures for emergency research in severe and moderate traumatic brain injury. Acta Neurochir (Wien) 147:633-640

4. Freeman BD, Danner RL, Banks SM, Natanson C (2001) Safeguarding patients in clinical trials with high mortality rates. Am J Respir Crit Care Med 164:190-192

T. C. Jansen · E. J. O. Kompanje (®) • J. Bakker

Erasmus MC University Medical Center, Department of Intensive Care,

P.O. Box 2040, 3000 CA Rotterdam,

The Netherlands

e-mail: e.j.o.kompanje@erasmusmc.nl

C. Druml

Medical University of Vienna, Ethics Committee of the Medical University of Vienna and the Vienna General Hospital, Borschkegasse 8b, 1090 Vienna, Austria

\section{K. Menon}

University of Cambridge, Addenbrooke's Hospital, Division of Anaesthesia,

Box 93, CB2 2QQ Cambridge, UK

C. J. Wiedermann

Central Hospital of Bolzano, Department of Medicine,

L. Böhler Street 5, 39100 Bolzano, Italy 